EDITORIAL: THE NEW PUBLISHING ARRANGEMENT

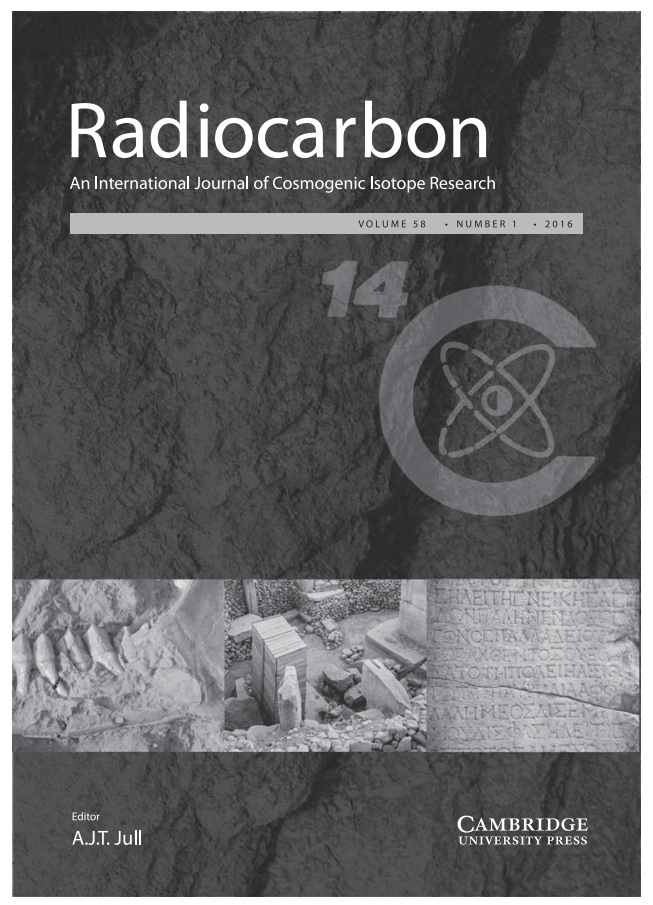

Radiocarbon has survived through 57 volumes as an independent academic journal. It has grown into an important journal focusing on radiocarbon and other cosmogenic nuclides and we are proud of the 27 years that the journal has spent at the University of Arizona.

Since its transfer from Yale to Arizona in 1989, Radiocarbon has always struggled to maintain the balance between its business model and the rapidly changing word of academic journals.

As many of you know, few journals are able to survive anymore independent of the commercial publishing world and Radiocarbon is no exception. Financial pressures are a constant challenge. We have therefore been looking for a suitable partner that can give us the exposure and electronic platform we need in this electronic era, and at the same maintain our vision as an academic publisher based in an academic institution. We have found that Cambridge University Press is a commercial publisher with a non-profit, academic base that fulfills our need. This was critical to our decision. Our journal maintains its academic independence and the University of Arizona still owns the title and copyright of the journal. CUP gives us the access we need to the very competitive world of academic publishing. Mark and I have been favorably impressed with the efficiency and quiet assurance of the transition to publishing through Cambridge.

In order to continue to grow, we also have changed our editorial board to restructure it in a way to highlight different roles. We will be introducing a more modern structure, with some associate editors handling the entire review process, up to the final recommendation to the editor-in-chief. We have a new submission website, mc.manuscriptcentral.com/rdc. Many authors may already be 


\section{iv Editorial}

familiar with this website, hosted by Scholar One, which is used by many other journals. We plan to go to bimonthly publication in 2017 , from the current quarterly publication.

We are excited about the new developments and will work with you if you have any problems or concerns about the new arrangements. We are sure you will agree as we move forward that the new arrangements will ensure many more years of publication of Radiocarbon.

With best wishes for 2016,

Timothy Jull

Editor, Radiocarbon 